Brit. J. industr. Med., 1955, 12, 163.

\title{
SAFETY CRITERIA IN ATOMIC ENERGY
}

BY

\author{
F. R. FARMER
}

From the United Kingdom Atomic Energy Authority, Industrial Group Headquarters, Risley

\section{The Problem}

The previous conference of this society dealt with the concept of tolerance levels in industrial activities. Today's conference has shown the importance of this concept in a new industry-that of atomic energy. The industry has an unfortunate history arising from its war-like introduction at Nagasaki and Hiroshima, and this has led to a considerable amount of confused thinking. Whenever atomic energy is mentioned, fear of an atomic explosion and the fear of death from a new cause are probably uppermost in men's minds.

The thesis I wish to put forward is not related solely to atomic energy, but deals with the more general problems of an approach to safety standards or tolerance levels. This subject is essentially one which is linked closely to the emotions rather than to the intellect, and it would be unfortunate if the association with atomic energy aroused emotion to such an extent that we could no longer think logically of the problems.

It has been stated that we should not be satisfied with our present achievement of safety in industry, nor should we be satisfied to remain just within tolerance levels laid down, but we should strive to reduce the hazard to zero. If this is the declared policy of the B.O.H.S., and is promulgated without qualification, what terms of reference do you give to those responsible for safety in a new industry? Is the policy to be followed regardless of cost ? Can the nation pay any price to ensure a marginal reduction of hazard?

These are some of the questions raised by the proposition that industry should never be satisfied with an achievement in safety at any level, and must be answered if industry is rightly regarded as only one part of national activity.

\section{The Varied Incidence of Accidents in Industry}

Hazards in industry are extremely varied ; for convenience in analysis they can be divided into a large number of categories, some giving rise to disease or ill-health in varying degree, others to accident or death. Some are easier to control or more easily anticipated than others, but fundamentally the sum total represents the hazard appropriate to a particular industry.

The reduction of the hazard may be brought about by the design of better equipment, by the adoption of new processes, or by better management exercised through staff selection, control, job planning. If unlimited resources are available any one of the hazards, and consequently the total, can be reduced.

I would expect to find that all industry had about the same accident rate, or that in industries showing higher than average figures the investment towards its reduction would be greater than the average. I find, in fact, a wide range of accident figures, and the difficulty in comparison arises from the definition of "accident". If this is based on time lost, other sociological factors would be introduced, such as the earnings in the industry, its past history, facilities immediately available, the goodwill of the industry.

A measure of hazard which has a more precise meaning may be taken from the number of accidental deaths, and these cover a range of $30: 1$ as between the highest and lowest given in the industrial classification for 1950 . For every 100,000 employed in any one industry, the safe occupations showed a death rate of about 3 per annum, whereas mines and quarries showed a rate of 80 per annum. A large number of our industries have a rate of 8 to 12 per annum, that is 1 in 10,000 . I am amazed at this diversity of risk, this inequality between the good and the bad, and in the light of the industrial safety policy declared earlier, I should expect to see an enormous effort applied to the reduction of risk in occupations showing the highest incidence.

\section{Reduction of Industrial Hazards}

Many attempts have been made to assess the cost of accidents in industry. I have not found a similar consistent attempt to determine the investment necessary to reduce the hazards. After a careful study of this question I have come to the conclusion 
that it is impossible, in general, to derive any realistic measure of the applied effort towards safety. We are not given a nicely tailored example of two similar industries side by side, or of one industry before and after investment in safety measures. Neither can the cost of accident prevention be measured by the mechanical guards erected, or by filters or scrubbers inserted in a gas stream. The total effort is the sum of these plus other factors of greater importance, but inseparable from the all-over effort towards industrial efficiency, which includes design, layout, and management, each of which can only include safety as one aspect.

In the absence of a precise yardstick which would enable me to say that this industry invests $f x$ toward accident prevention whereas that industry invests $f y$, I can only make a generalized approach. Does it use only the equipment known to be of the highest quality giving safest operating conditions? Are the best techniques of management applied ? Are the operators selected more rigorously and better trained than those in other industries?

I do not think that these conditions are met with in our dangerous industries, but are in fact found in the efficient and successful industries which are operating with average or lower than average risk of accident. On the evidence available I believe that I am justified in coming to the conclusion that the effort applied towards the total elimination of accidents is not determined by good intentions, neither is it regulated by the current risk within an industry, but is, in fact, one aspect of wider economic considerations. Safety is only one aspect within the economic field and I am sure that few industries can afford to operate in any way other than the most economical. In spite of its numerous assurances to the contrary, industry does not do all that can be done to eliminate risk of accident, for this would cost too much. In order to survive, first as a nation, and secondly as an industry, we are forced to operate at minimum cost. This may be modified under certain conditions as a national policy.

\section{It Pays to be Safe}

The dictum of every safety officer, and the theme in all safety journals I have read is, "It pays to be safe". This implies that steps taken towards safety operate towards greater economy and, in fact, in choosing to produce the cheapest article, industry chooses the route of safety. This can only be true up to a point, but in retrospect it is clear that the big strides towards reducing accidents in industry in the last 20 years have been made in the course of reorganization. In a growing industrial community each change has led to greater economy, and in many cases the change, of process or plant or of production method, is forced by competition.

In assessing maximum economy, accidents and deaths arising from industrial activity will all contribute towards the cost of production. Much has already been said and written on this subject, and it is often inferred that industry could not pay the bill for lost time and compensation arising from accidents, and for this reason is forced to improved and safer production. I cannot believe that this is in fact the position : it is inconsistent with the widely diverging death rate in our industries. Can one industry afford to operate at 80 deaths per year per 100,000 employees while another operates at 10 per year? The urge to reduce the lower figure of 10 to 9 or 8 cannot be based on directly incurred charges; the industry having 80 deaths per year would be forced to spend a large percentage of its income on preventive measures. It is more consistent to deduce that accidents play a minor role in production costs and that a continued reduction of risk is a secondary effect in industrial reorganization.

If in one industry the accident rate is very high, it is possible that labour will be loath to move into that industry and will demand higher wages, danger money, etc. The principle of danger money is already established, but this is more closely related to the job or to the severity of the risk rather than to the industrial economy and the probability of risk. There is comparatively little sign of reluctance to enter a hazardous industry, such as explosives; nor is there a particular consciousness of danger within such industries except possibly in the most hazardous-mines and quarries. Other aspects of the job outweigh the danger, and very few of us consider the risks we run in industrial and nonindustrial activities and most people assert that their job is safer than investigators would have them believe.

\section{Is There a Balance between Industrial and Non-industrial Hazards ?}

In considering the motivation for accident reduction, I have looked for modifications of the doctrine of maximum economy. It could be argued that this doctrine in its simplest form is the impersonal operation of the employer. If the employee were particularly conscious of risk he would modify the simple approach by seeking to impose restrictions in recruitment or by wage demands. In a highly organized state the employee also exercises control through his elected government by the imposition of regulation and inspection. I would expect both of these employee-directed impulses to be related to the health and well-being of the community. For 
instance, in war time greater risks are tolerated, and, in an unhealthy community, the particular health hazards of industry do not excite comment. I would not expect an employee to be conscious of a risk which is small compared with the risks he already accepts in life, nor would he demand a standard of perfection from 7 a.m. to 5 p.m. which is vastly different from that prevailing outside these hours. This argument appears reasonable if we are comparing similar phenomena, if the results are the same, and if they are similarly understood.

The greatest risk we run is that of dying from natural causes. We are used to this idea, although there is an increasing reluctance to accept it as inevitable and we like to postpone it for as long as we can. We, as a nation, are prepared to invest a considerable sum in an attempt to delay death and to remove the unpleasantness and inconvenience of ill-health, which itself carries a probability of death, and certainly makes us conscious of death around the corner.

Twenty years ago of every 1,000 live births 220 died before the age of 45 ; today this number is 110 , or, 110 people per 1,000 born reach the age of 45 who would formerly have died. Until we reach the age of 45 or over we are not very worried by the diseases of old age. Both as individuals and collectively as a nation we are concerned about death in the young and middleaged and for every 100,000 people in this category today the death rate is 150 per year. This is made up of deaths from a variety of causes -influenza, pneumonia, tuberculosis, malignant diseases, and also the special category of death from violence. This category includes road deaths, deaths from falls, burns, drowning, suicide, and contributes to the total about 30 to 40 per 100,000 . In other words, a worker is four times more likely to meet a violent death outside his working hours than within them. No single cause is outstanding other than violence which itself is subdivided, and our national investment is spread over, partly towards prevention, partly towards reduction in severity. If we wished we could concentrate our effort towards a narrow front or increase our effort in one direction. In recent years we have increased our expenditure on the National Health Service, and we have already reached the position where some say that we have reached or exceeded our ability to pay for these services. Others wish to increase the Service hoping to achieve better health through more frequent medical attention or improved hospital facilities. We all know that deaths occur today which could be prevented if we were prepared to invest a greater sum in safety. Apparently we do not choose to do this and we are only prepared to insure ourselves against these natural hazards at a premium of $£ 10$ per head per annum.

\section{The Community Outlook on Hazards}

Against this background, in which we see that a young population of 100,000 can expect 150 deaths per year, the hazards of industry can be seen in perspective. An additionally imposed rate of fewer than 10 per annum represents a $7 \%$ increase, and there is no reason to expect that this $7 \%$ will respond to treatment with greater ease or lower expenditure than any other cause making up the total. On the other hand, a rate of over 70 per annum per 100,000 employed represents an increased risk of death of $50 \%$.

I suggest that in relation to known and existing hazards the community unconsciously makes a comparison, and we should expect that as the greater risk of death from natural causes is reduced then there would arise a growing dissatisfaction with any additional hazard which has not similarly decreased. The trend in industry has followed the trend in national health and I would expect both to improve without necessarily requiring greater effort. There remain today two outstanding causes for dissatisfaction, death from road accidents and from accidents in mines. These are in a similar category: both are the effects of violence; neither can remotely be called an "act of God" and accepted currently as an evil to be borne by the human race. In both cases the extent to which effort is applied towards a reduction is determined for the most part on an economic basis, modified only slightly by pressure of public opinion.

The frequency rate for road deaths is 12.5 per 100,000 of the male population and as such is comparable with the rate in many industries, but it is only one-sixth of the rate for mines.

\section{The Introduction of New Hazards}

Earlier, I mentioned the effect of emotion and I agree that individually and collectively we live as much by the emotions as by the intellect. I have no desire to belittle the value of emotion, but too often a muddled gushing of sentiment is offered in place of a reasoned policy.

I believe, however, that policy should first be decided in an unemotional atmosphere and that emotion should be used to implement this reasoned policy which will still take human values into account.

As a nation our policy is largely decided by $£$ s. $d$. and essentially all of our industrial activities are similarly determined. However, if a new hazard appears, this premise may no longer be applied. 
When once an uncertainty or fear begins to spread a very much greater effort is demanded by the public. Fear is undoubtedly catching and may be set off by trivial things with or without substance. In our everyday life the fear of poliomyelitis is very marked and its effect on our national economy is far greater than its relative incidence compared with better known afflictions. In this case the fear may or may not be justified, but once initiated it is not easily dispelled. This point was made by the Chief Medical Officer in his report for 1950 :-

" The outbreak [of poliomyelitis] in the Isle of Wight gave some measure of the public alarm ; it spoiled the holiday traffic and deprived thousands of their vacation in this lovely island. In spite of the special vigilance of the practitioners and the unusual readiness of the people to consult them during the five weeks of the outbreak, only 49 cases were notified, of which 41 were paralytic. These 49 cases were specially studied and most were found to be linked in a chain involving, with one or two exceptions, only permanent residents in the island. It is unlikely that the incidence among holiday makers was above the average for the whole of the country. Clearly the public alarm, kindled by spectacular journalism, was unnecessary and unrealistic.

"The public anxiety also tends to be exaggerated because the outcome of the disease is not generally understood."

Similarly the advent of atomic energy is in the public mind associated with fear of the unknown and the horrific-with sterility, the loss of hair, with abnormalities in future generations.

Against this background and that of current industrial trends, what standards should we adopt in safeguarding the future development of this new industry?

\section{Application to the Early Development of Atomic Energy}

You have already heard how tolerance levels have been laid down by international agreement and how these have been measured and enforced at Windscale. We are aware that most of the tolerance levels contain a considerable safety factor but in addition we choose to insert further safety factors in our application of these levels. In this way we allow for our lack of knowledge in the chain of events from plant operation to the point at which the tolerance level could apply; that is, from plant operation to airborne hazard, or from effluent emission to human intake or from a gamma-ray source to the point of exposure. For the first time in the development of a major industry the following conditions exist : (1) Freedom from competition or any externally imposed monetary scale for its product, and (2) an initial awareness of the hazards involved in the industrial operations.
Under these conditions the apparently conflicting demands of economy, simplicity, and speed of development were heavily outweighed by the need for safety, and, at considerable cost, the industry has achieved a record which is outstanding by comparison with any major industry today. This is true not only in relation to the special hazards of radioactivity but also in relation to the commonly accepted form of accident arising from any industrial operation.

In the latter category of deaths entirely dissociated from radioactivity, our rate is one-third to onequarter that in the engineering, chemicals, gas, and electricity undertakings, and yet these industries consider their own records something of an achievement. Our accident rate is also running at a far lower figure than the average in industry today.

The radioactive hazards are, as you know, divided into the two groups of internal and external radiation. In the former group, not one single case has occurred showing any symptoms whatsoever of temporary over-irradiation. Our yearly records of over 100,000 films show that no employee has exceeded the average maximum tolerance level and that over $96 \%$ have received an exposure of less than one-tenth of this level.

Most of the airborne tolerances are based on a life-time accumulation so that small hour-by-hour variations are of less importance than is the case with many industrial hazards giving rise to acute conditions. Even so, our intensive air-sampling campaign has shown that over $98 \%$ of samples lie at a level of less than the long-term tolerance.

\section{Application to the Longer-term Development of Atomic Energy}

The record quoted is one of which we are justifiably proud, but it has been achieved at considerable cost. We are already moving away from the initial phase and the nation is expecting to see big strides made in peace-time applications. If you accept the premise that atomic energy is an essential industry then it must go ahead in competition with other industries. The money invested is an alternative to investment in some other enterprise.

Concurrently with the urge to develop competitively, we have gained a considerable understanding of the hazard and its control. I believe that the tolerance levels accepted by international agreement are as realistic as most tolerance levels for industrial hazards. Our measuring instruments are, for the most part, capable of infinitely more sensitive determinations than those for the chemical poisons even in relation to the limits laid down. This enables us to operate with greater confidence, and with a high 
degree of certainty that our operations can be conducted within the tolerance levels. I am of the opinion that our probability of exceeding the danger level is far less than 1 in 100,000 per annum, that is less than one-tenth of the current industrial death rate, or less than one-fortieth of the probability of death by violence.

If the tolerance levels move up or down, our design and operations can follow-at a cost or with commensurate saving. If this new industry is to progress competitively it is essential to ensure that realistic levels are agreed and always maintained as such, following the growth of knowledge and operating experience. This does not relieve the industry of its obligation to work to the highest possible safety standard within any given economic framework and that we should always pursue the goal of zero risk with the expectation that greater safety and greater economy will advance together through the exercise of the best engineering and management practices available.

\section{Discussion}

Dr. J. F. Loutit (Radiobiological Research Unit, Harwell), in opening the discussion, said that the records of the atomic energy industry today were beyond reproach, but it had never been expected that there would be troubles in the first few years. The International Commission on Radiological Protection and its British national counterpart, which were responsible for setting permissible levels, had in their calculations to envisage that in the industry in the future employees would go on in routine jobs involving exposure to radiation for 25,35 , and perhaps 40 years. It was essential for this reason to have these safety factors. Furthermore, there was very little experience of the hazards from plutonium and fission products, and it was possible to estimate only on the basis of experience with other radioactive materials such as radium. Thus there might be some doubling up of safety factors with regard to the internal hazards.

The safety factors against the hazards from external radiation were in his view very slim indeed. In spite of their 50 or 60 years of experience with external radiation they had no truly scientific data at all about its hazards to man. They had records, it was true, of the $x$-ray martyrs and knew that people had died of bone diseases and of blood diseases, but they did not know the doses which those people had received. It was only possible to hazard guesses, and to relate those guesses to the observed clinical results.

It was their best guess that $\mathbf{0 . 3}$ röntgen per week in tissue would not cause damage when spread over a 30 -year or 40 -year working life $(0 \cdot 3$ röntgen per week was approximately 7.5 milliröntgens per hour). What happened if the dose-rate of 7.5 milliröntgens per hour was exceeded? Some thought that it was perfectly permissible provided one kept within the global dose of
0.3 röntgen per week, but not everybody took that view, notably the Swedes.

Blood counts had been somewhat discounted earlier in the Conference, and he personally was in agreement : but data from Sweden (Helde and Wahlberg, 1953) had been published on blood counts of men in different types of radiological work. They received varying doses from 1 to 100 or so milliröntgens per week above the local background and the abnormalities in their blood had been scored in terms of percentages. It was noted that some groups had $30 \%$ of abnormal leucocytes with relatively high doses within the permissible range. Others had the same percentage of blood changes with average doses 100 times lower. At first sight there seemed to be no sense in what was found, but when Helde and Wahlberg considered these groups in terms not of the global dose per week but of the dose-rate the anomaly disappeared and there was a beautiful correlation between percentage abnormalities and dose-rate. That was now generally accepted in Sweden.

At Harwell, Dr. Mole had attempted to survey the literature to assess the value of blood counts (Mole, 1954). Although many of the $x$-ray and radium martyrs died of aplastic anaemia, only very few records were available of prior blood counts. These showed that a few months before their deaths they had absolutely normal figures.

If a man was due to die of aplastic anaemia in a month or so, one might have expected some signs of warning. On the other hand the observation may not be so surprising, because one knew what happened in the case of other tissues, such as the liver. Function could be maintained by a grossly damaged liver, and it was only at the last moment that there were demonstrable chemical signs of liver failure. Similarly, it was possible that damaged bone marrow could keep the elements of the peripheral blood at normal levels until a point of exhaustion was reached.

There were, therefore, those two opposing views, the Swedish view and the one which he had just postulated. There was still room for operational research in these matters and not only from the conventional clinical point of view of blood counts. From the results of experimental animal work at Harwell he considered damage to the gonads as most important.

Mice had been chronically irradiated from about the age of 3 months until they died. The white cell count, which was regarded as the most sensitive index in the blood, remained perfectly normal, but it was seen that male fertility fell to zero within three months, and female fertility within five months. Thus male fertility and female fertility fell demonstrably long before there was any abnormality in the white cell count, and in fact there had been no abnormality in the white cell count, even at death. It was noted that testis weights paralleled closely male fertility.

He would like to ask industrial health officers whether it was possible in the twentieth century to make some objective investigation of fertility, apart from scoring births. Was it possible in this enlightened age to obtain some objective measure like blood counts, such as sperm counts, on industrial workers to see whether the safety 
measures which were taken as regards external radiation were in fact as safe as one hoped that they were?

American workers in Rochester had shown that with dogs the same sort of thing occurred. With doses of one röntgen per day after two years the dogs were at least grossly infertile. He was not saying that the sexual behaviour of mice or dogs was comparable with that of man, but he thought that there ought to be more data on man than were available at the moment.

Dr. E. F. EDson (Pest Control, Cambridge) thought that the main point for discussion was the problem of whether too much money was being spent on protection (a) in industry as a whole and $(b)$ in the new atomic energy industry. That was a matter on which many people in industry must already have pondered. The question was very often asked, "Why do you spend so much money on protecting the worker when his chance of being killed on his way home on his motorcycle is already so much greater than the risk which he runs in the factory?"

It might be said that road accidents were a major source of risk to people today, as indeed they were, and might perhaps be an even greater source of risk to the next generation, and that not enough was being done about it. To say that was to see only one side of the picture, however, overlooking the work done by local authorities, voluntary organizations, the police, and, indeed, by taxpayers generally. The total amount of money and effort which was being spent on improving the roads and decreasing road casualties was already large. Similarly, a good deal was heard about the difficulty of controlling morbidity and mortality in mines, quarries, and other hazardous industries. The major competitors with atomic energy in the production of power were oil, which had to be brought to this country by sea, a somewhat hazardous occupation, and coal, production of which had one of the highest hazard figures in industry. If the present safety levels in atomic energy factories continued then atomic energy was probably the safest form of power as far as risks in production were concerned.

The public emotions and apprehensions were often blamed for large governmental expenditure on safety in atomic energy works. There was no point in negligently adding to the existing risks of life where there was an opportunity to control new hazards. In due course it would probably be possible to settle down to a lower cost per worker per annum for protection when it was possible to agree on the proper needs of the situation. We were probably providing some over-protection at present in the atomic energy industry. The lesson of the beryllium industry, however, must not be forgotten. The beryllium industry was carried on for many years without any significant casualties, but during the last 15 years it had been shown to have produced a large number of cases, many of which, the early ones, had almost been missed. Nowadays the protection of the worker in the beryllium industry costs almost as much as in the atomic energy industry. The trouble arose because the degree of changes and occupational hazards had not been detected in the early stages ; he had said earlier that he felt the atomic energy authorities should not be too quick to blame themselves for spending too much money on radiation protection. Public opinion, which was important, would prefer them to spend a little more money in the first 10 or 25 years, rather than to have a large amount to pay in the next generation.

Mr. J. R. Hodkinson (Safety in Mines Research Establishment) said that one might conclude from Mr. Farmer's paper that, as fatalities in atomic energy work were so very much lower than in the safest of other industries, their figure might be allowed to rise from $0 \cdot 1$ per 100,000 to 1 or 2 per 100,000 in return for a saving in the present very large expenditure on protection. He thought, however, that the accident rate was not so simply related to safety expenditure; that there was no stable, half-way position in radiation protection ; that a position of control was reached only when the hazards had been reduced to a very low level.

The President asked whether the workers in coalmines had anything to say on the problem of whether too much money was being spent on protection.

Dr. J. M. RogAN (National Coal Board) remarked that accident rates in the mines were extremely high, but they were about half the rate in German mines (the present death rate in British mines was about half what it had been 20 years ago) and only one-third the death rate in the American mines.

The coal-mining industry was now reaping the harvest of the conditions which had existed many years ago. There was a considerable amount of pneumoconiosis in the industry. The disease had developed insidiously as a result of dirty conditions underground once thought to be harmless. He would therefore advise the new Authority which was concerned with atomic energy that so long as they were doubtful about their permissible levels they ought to err on the side of safety. In coalmining they found it difficult to attract men into the mines, although this was necessary for the country's survival. It might be that within the next 20 years the country's survival would also depend on atomic energy, and unless those concerned did all that they could within reason to protect their people now, they might be in a very difficult position in the future, especially if they found that the gonads had been affected.

Mr. M. JACOBSEN (Chemical Workers Union) said that atomic energy was a comparatively new industry in which, because it was new and because not enough was known about permissible levels, safety precautions had been instituted which might even be in excess of what was really necessary. That ought to be regarded as a boon to the community, because some of the older industries, like coal-mining, had not had the benefit of such an attitude and were now suffering from the results of that neglect, and had been doing so for the last hundred years. More money should be made available to reduce hazards elsewhere to the level which the atomic energy industry aimed at achieving.

\section{REFERENCES}

Helde, M., and Wahlberg, T. (1953). Acta radiol., Stockh., 40, 435. Mole, R. H. (1954). J. clin. Path., 7, 267. 